\title{
Introduction: Reflections on Nancy Abelmann's Legacy
}

\section{ELEANA KIM AND JESOOK SONG}

Nancy Abelmann passed away on January 6, 2016, at the age of fifty-six. She received her PhD from the University of California, Berkeley in 1990, after completing her dissertation under Nelson Graburn. That same year, she was hired by the University of Illinois, Urbana-Champaign, where she worked for two and a half decades. She was a beloved teacher, mentor, and colleague to many, and she was a key figure in multiple departments and centers. At the time of her death, she held the Harold E. Preble Professorship in Anthropology, Asian American Studies, East Asian Languages and Cultures, and Women and Gender Studies and was also Associate Vice Chancellor for Research.

Keywords: class, education, family, gender, Korea, mentoring, Nancy Abelmann, social movements, transnationalism, United States

M ANY OF US WHO knew Nancy are at a loss when we try to find a felicitous way to narrate who she was and the countless things that she did. Part of the challenge lies in her avid approach to life and work, and the boundless eclecticism of her scholarship. Throughout her career she was engaged in numerous original and rigorous research initiatives and collaborations, which have left us with too many threads to neatly interweave. Indeed, she might have assured us that establishing coherence or finding a single way to bring these diverse things together was utterly unnecessary. Nancy-our beloved friend, mentor, and colleague - was not merely a generous person to each of us, personally and professionally. She also inspired many other academics and readers through her zest for ethnography and her consummate storytelling. Her many gifts make our job of remembering her legacy a daunting one, one that can only be performed collectively (see figure 1).

Given the challenge of fully capturing the myriad ways that Nancy influenced individual scholars, multiple fields of study, and institutional programs, a quick survey of her career offers the most ready picture of how truly prolific she was as a scholar and mentor. In the twenty-six years that she was a faculty member and administrator at the University of Illinois, Urbana-Champaign (UIUC), she advised thirty-two doctoral dissertations, served on sixty-three committees, informally mentored countless students and (junior) colleagues, facilitated dissertation and book-writing workshops, and shepherded major national fellowship applications for her colleagues. An even larger number of people benefited from her scrupulous attention to their writing and ideas-with drafts of their writing transformed by her detailed comments and thorough copy edits. She was a

Eleana Kim (eleana.kim@uci.edu) is Associate Professor in the Department of Anthropology at the University of California, Irvine. Jesook Song (jesook.song@utoronto.ca) is Professor in the Department of Anthropology at the University of Toronto. 


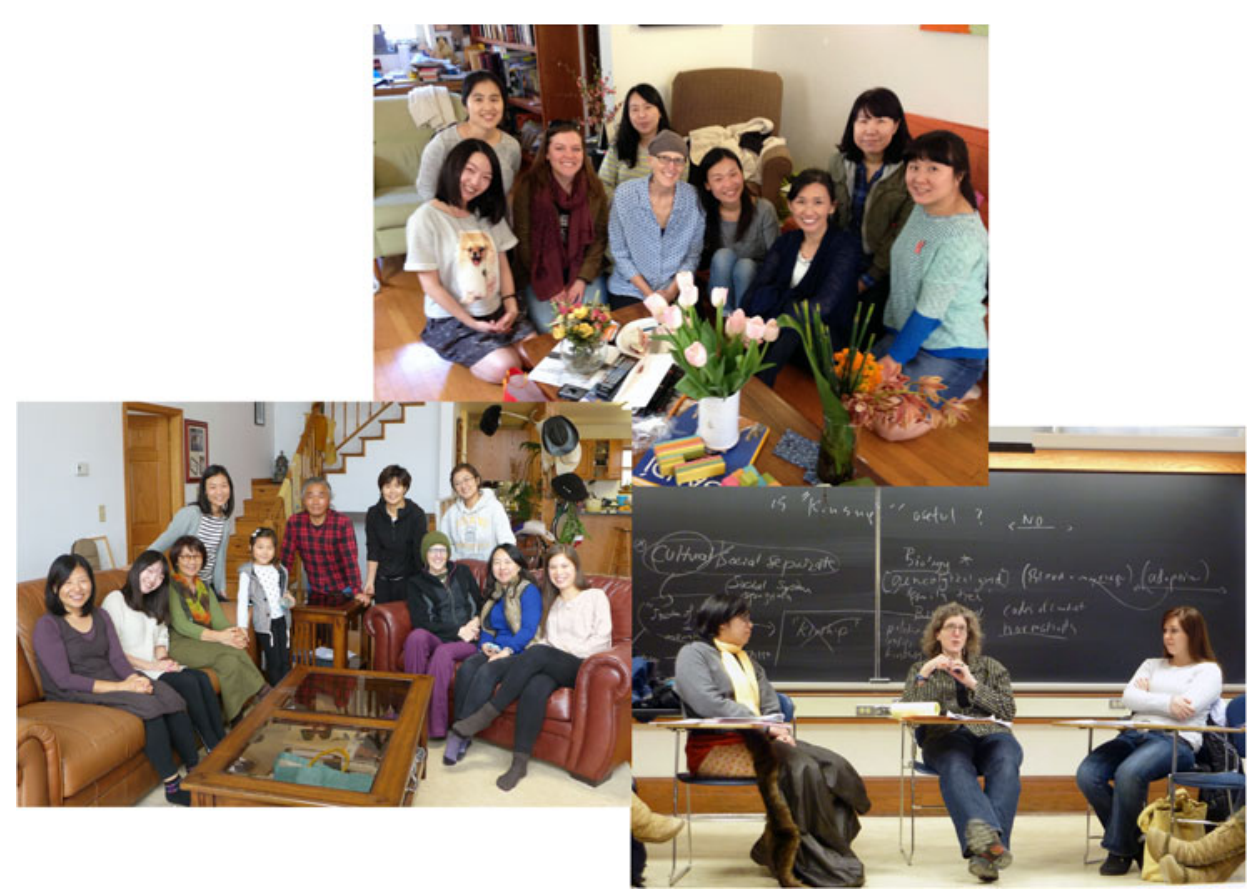

Figure 1. Nancy socializing with friends and teaching students in her class about kinship. Photos by Ga Young Chung and Yoonjung Kang.

prolific writer, having published three single-authored books, two co-authored books, and two edited volumes, and was widely sought as a speaker, giving more than 170 presentations across nearly all continents, including in Asia, North America, Europe, Oceania, and South America. Her professional service also reflected her intellectual commitments. She served as a mentor for the Social Science Research Council's Korean Studies Workshop for Junior Faculty and Dissertation Writers (mentoring a total of forty-two fellows), as president of the Society of Urban and Transnational Anthropology, as a member of the Korea Advisory Board for the Social Science Research Council, and as a member of the Korea Foundation North American Advisory Committee. Her wide-ranging scholarly expertise is further reflected in her service on the editorial boards of Anthropological Quarterly; Asian Educational Media Service; Asian Journal of Women's Studies; Journal of Korean and Japanese Cinema; Korea Journal; Social Politics: International Studies in Gender, State and Society; and Social Science History; as well as the book award committees for the Association for Asian Studies (AAS) Northeast Asian Council, the Society for East Asian Anthropology, the Society of Urban and Transnational Anthropology, and the Association for Asian American Studies. In addition, she was a founding member of the Asian American Studies Program at UIUC in 1997, which garnered direct and indirect support for newly emerging Asian American studies programs and became a department in 2002.

Nancy was a visionary institution builder and field changer. She embraced interdisciplinarity at a moment when Korean studies and East Asian studies were much more bounded fields than they are today, and her contribution to opening up those fields 
cannot be understated. Her intellectual engagements and research collaborations helped to bring urgent contemporary concerns into area studies by enabling interdisciplinary dialogues with transnational and urban studies, film studies, Asian American studies, education, and gender studies. Although she was to later develop and contribute to the institutional infrastructures and interdisciplinary collaborations that fundamentally changed Korean studies, it was her incisive analyses of the 1980s Korean democratization movement and the 1992 Los Angeles uprising that first brought contemporary political issues directly into Korean and Asian studies in the mid-1990s.

Her first two books, Blue Dreams, which was co-authored with John Lie, and Echoes of the Past, Epics of Dissent (based on her dissertation), were published within a year of each other and exemplify the significant impact her work had on the fields of Korean studies and East Asian studies, which had been dominated by literary and historical studies of the premodern and early modern periods. ${ }^{1}$ In her home field of anthropology, along with senior scholars like Laurel Kendall, Roger Janelli, and Dawn Yi Lim, Nancy helped to expand studies of contemporary South Korean society and gender. But contributions of anthropologists and sociologists of South Korea in the social sciences were mostly marginalized by the theoretical and political preoccupations of political scientists. Methodological and theoretical incompatibilities between the humanities and social sciences further divided Korean studies into disciplinary silos. As any close reader of Nancy's work will know, she was also keenly interested in the humanities-in part influenced by the "literary turn" in anthropology, but also because of her inherently aesthetic sensibility. She frequently drew upon expressive cultures-poetry, novels, paintings, and film-as cultural evidence in her writing and analysis.

For scholars in Asian American and ethnic studies, Blue Dreams was a revelatory and pioneering text, offering a timely, transnational analysis of Korean immigrants in the United States that skillfully used ethnography to unpack one of the most painful periods in Asian American history. It was published just three years after the 1992 Los Angeles "riots," which brought unprecedented media and public attention to Korean American immigrant communities. This book acted as a crucial empirical and analytical resource, placing Korean immigrants into longer histories of colonialism, division, war, and military authoritarian dictatorships and writing explicitly against prevalent sociological analyses that used static cultural frameworks to explain Koreans as successful "ethnic entrepreneurs.” Based on fifty in-depth interviews, Nancy and Lie presented a nuanced and historically situated analysis of the political consciousness of Korean Americans, and the centrality of transnational connections to understanding the diversity of views and experiences within the diasporic Korean community in Los Angeles. In these ways, Blue Dreams was groundbreaking, and it has become a canonical text, offering a model of what Asian American studies_or a critical, internationalized American studies and transnational Asian studies - can be.

In Korean studies, Nancy's first monograph, Echoes of the Past, Epics of Dissent, also made a significant impact, offering a political ethnography of Korean peasants' land disputes at the peak of South Korea's democratization process. It uniquely captured the

\footnotetext{
${ }^{1}$ Nancy Abelmann and John Lie, Blue Dreams: Korean Americans and the Los Angeles Riots (Cambridge, Mass.: Harvard University Press, 1995); Nancy Abelmann, Echoes of the Past, Epics of Dissent: A South Korean Social Movement (Berkeley: University of California Press, 1996).
} 
emotional and cultural experiences of people mobilizing for political change in ways that gave fine-grained ethnographic texture to studies of South Korean "civil society." Linda Lewis's review of it in the Journal of Asian Studies (JAS) commended it for being "the definitive study of the tumultuous 1980s, a truly remarkable 'particular moment' in modern South Korean history." ${ }^{\prime 2}$ In anthropology, it contributed to a nascent literature on social movements to ask fundamental questions about political processes, emergent subjectivities, culture, and power. In the study of social movements, it helped to shift the theoretical discussion beyond Western sites, while also attending to the paradoxical position of the (white) American ethnographer (and US-trained knowledge producer), deeply embedded in the Cold War politics of the Korean peninsula. A photo taken during the time she did her research illustrates this point clearly: Nancy is depicted at the frontline of a protest against the US military and South Korean military coup, holding a picket sign proclaiming, "Yankee Go Home!"

Both Blue Dreams and Echoes of the Past were field-changing and inspiring texts, leading the way for new generations of transnational Asian American studies scholars, as well as studies of South Korean social movements and the rapid transformations in post-democratization South Korean society. Nancy turned to examine those rapid transformations in her next major work, The Melodrama of Mobility, which received the 2004 Leeds Prize from the Society for Urban/National/Transnational Anthropology and the 2014 Im Seok-chae Award from the Korean Society for Cultural Anthropology (for best translated book in Korean). ${ }^{3}$ In this ethnography, she continued in the tradition of scholars like Martina Deuchler and Laurel Kendall, who had laid the groundwork for the study of Korean women and gender. Influenced by other feminist anthropologists who foregrounded the experiences and voices of women as well as ethnographic trends in narrative analysis and life stories in anthropology, Nancy drew upon the personal narratives of eight women whose lives coincided with the most dramatic social, cultural, economic, and political transformations of South Korea's "compressed modernity,"4 and who also had just endured the economic nightmare of the Asian Financial Crisis (the 1997-98 "IMF Crisis"). The women's narratives of class mobility, education, and modernity reveal the complex, ambivalent, and what would now be described as "precarious" lives of the women, and how they made sense of and struggled to construct moral values and meaningful lives as workers, mothers, and wives. Her dedicated and sophisticated analysis of gendered experience in The Melodrama of Mobility centered the significance of gender studies in East Asian studies and helped to bring the significance of East Asian modernity to studies of gender. Furthermore, Nancy's contribution to making gender a prominent scholarly object of analysis is inseparable from the emergence of women scholars' leadership in the fields of Korean and East Asian studies.

Melodramatic soap operas and films were frequent touchstones in the women's narratives in Melodrama of Mobility, precisely because these popular media grappled with

\footnotetext{
${ }^{2}$ Linda Lewis, review of Echoes of the Past, Epics of Dissent, by Nancy Abelmann, Journal of Asian Studies 57, no. 2 (1998): 556.

${ }^{3}$ Nancy Abelmann, The Melodrama of Mobility: Women, Talk, and Class in Contemporary South Korea (Honolulu: University of Hawai'i Press, 2003).

${ }^{4}$ Chang Kyung-Sup, "Compressed Modernity and Its Discontents: South Korean Society in Transition," Economy and Society 28, no. 1 (1999): 30-55.
} 
critical debates about class, social mobility, gender, and identity "in times of great social transformation ... when the moral universe is unsettled." visual culture led to another of Nancy's major scholarly contributions: popular media in postmodern South Korea. Well before the "Korean Wave" had become a household word, Nancy was fascinated by how the moral contradictions and conundrums of modernity - in relation to social relations, cultural values, and national identity-were worked out through popular melodramatic narratives. Her 2005 coedited volume with Kathleen McHugh, South Korean Golden Age Melodrama: Gender, Genre, and National Cinema, is a foundational text in the study of South Korean media and popular culture, as well as South Korean modernity. ${ }^{6}$ It was the first study in English (and perhaps in any language) to analyze postwar South Korean cinema. Nancy and McHugh posited that the compressed modernity of postwar South Korea rendered people's everyday lives highly dramatic. "Thus, instead of maintaining generic boundaries between the realistic and the melodramatic, between lived experience and fictional narrative, South Korean cinema construes melodrama as the most efficacious mode of realism." ${ }^{\text {"7 }}$ The collected volume not only offered historically grounded, gendered analyses of South Korean modernity and film, asking us to consider South Korean Golden Age cinema to be as significant as other national cinemas, such as Italian Neorealism or the French New Wave, but also exemplified Nancy's interdisciplinary, collaborative, and mentoring approach to scholarship. Many of the authors whose work was included in that volume were junior scholars or graduate students, and the volume literally helped to plant the seeds for what has since become the most rapidly expanding area of Korean studies, and transnational Asian studies more generally, namely Korean/Asian film studies.

Nancy maintained a website (nancyabelmann.com), which continues to provide an archive of her written work, collaborations, and teaching. Her syllabi are wonderfully creative in their pedagogical approaches, and many of them include information about the Ethnography of the University Initiative (EUI) at UIUC, which was part of her commitment to collaborative knowledge production and innovative pedagogy. Her collaborator and mentee Jiyeon Kang, in this issue of JAS, writes, "EUI offers a glimpse of Nancy's interest in and devotion to the university. It was an object of her anthropological inquiry, a community in which she strived to be a good citizen, and a society for which she envisioned new ethics of living with others..." Kang's essay included here reviews the significance of Nancy's most recent research agenda, which, from the mid-2000s until her passing, engaged her enduring interests in gender, family, class, transnationalism, social mobility, and pedagogy by centering on the intersection of transmigration studies and the ethnography of education and the university. Kang and Nancy were collaborating on a project called New Global Civilities: The Mobile Undergraduate in the U.S., China, and South Korea, a transnational comparative project focused on Chinese international students in South Korea and in the United States, and Korean international students in China and the United States. This project was an extension of ongoing research collaborations Nancy had engaged in since beginning the EUI in 2003 and The American

\footnotetext{
${ }^{5}$ Nancy Abelmann, The Melodrama of Mobility, op. cit. note 3, 27.

${ }^{6}$ Kathleen McHugh and Nancy Abelmann, eds., South Korean Golden Age Melodrama: Gender, Genre, and National Cinema (Detroit, Mich.: Wayne State University Press, 2005).

${ }^{7}$ Nancy Abelmann and Kathleen McHugh, "Introduction: Gender, Genre, and Nation," ibid., 4.
} 
University Meets the Pacific Century Project in 2010. The EUI has also become an inspiration for other anthropologists and institutions to explore their own ethnography of the university, such as Tania Li's undergraduate course at the University of Toronto.

The huge investments that Koreans and Korean Americans make in education gained international stature after President Obama's 2011 State of the Union address, in which he praised the culture of respect for teachers as "nation builders" in South Korea. Of course, scholars of South Korea recognize the double-edged sword of Korea's "education fever," which has fueled secondary and tertiary economies in tutoring, after-school programs, homeschooling, and study abroad for many South Koreans who are desperately devising strategies for upward mobility in a highly competitive society. Nancy spearheaded the critical examination of the double-edged sword of Korean education, partially as a continuum of her earlier interests in the unwaged labor of mothers whose gendered work for class mobility strenuously focused on their children's education, ${ }^{8}$ and in conjunction with her EUI project that produced her 2009 monograph, The Intimate University, which examines racialized and ethnicized dynamics among and within Asian immigrants' children, families, and churches. ${ }^{9}$

This critical examination of Korean education lives on in a series of collaborative projects that reconsider the agency of Korean parents and the experiences of their children, which do not necessarily fit the stereotypical, conventional models of "success." Those works include No Alternative?, co-edited with Jung-ah Choi and So Jin Park, and South Korea's Education Exodus, co-edited with Adrienne Lo, Soo Ah Kwon, and Sumie Okazaki. ${ }^{10}$ These co-edited books and numerous journal publications directly and incisively examine South Korea's "education fever" from different angles and vantage points, and grew out of comparative analysis and evolving collaborations with colleagues and junior scholars from different locations and disciplines. Although it may not have been obvious when these projects began, now that they have come to fruition, it is clear that Nancy not only helped to establish a new field of study, but also actively mentored and trained future generations of scholars in transnational and interdisciplinary Korean education studies.

Finally, along with these ongoing conversations about education and the university, Nancy continued her ethnographic engagements with women who appeared in The Melodrama of Mobility by tracking the migrations of their children in Korean American Families in Immigrant America (co-authored with Sumie Okazaki). ${ }^{11}$ She was also drawn to new areas of research and collaboration, including a collected volume project she had in mind on National Public Radio's StoryCorps, and what it could reveal about kinship, race, class, public intimacy, and storytelling in contemporary America. There were doubtless many other inspired and timely projects that would have drawn on and expanded

\footnotetext{
${ }^{8}$ See Abelmann, The Melodrama of Mobility, op. cit. note 3.

${ }^{9}$ Nancy Abelmann, The Intimate University: Korean American Students and the Problems of Segregation (Durham, N.C.: Duke University Press, 2009).

${ }^{10}$ Nancy Abelmann, Jung-ah Choi, and So Jin Park, eds., No Alternative? Experiments in South Korean Education (Berkeley: University of California Press, 2012); Adrienne Lo, Nancy Abelmann, Soo Ah Kwon, and Sumie Okazaki, eds., South Korea's Education Exodus: The Life and Times of Study Abroad (Seattle: University of Washington Press, 2015).

${ }^{11}$ Sumie Okazaki and Nancy Abelmann, Korean American Families in Immigrant America: How Teens and Parents Navigate Race (New York: New York University Press, 2018).
} 
Nancy's fascination with gender, social mobility, political subjectivities, modernity, transmigration, and transnationalism. As this brief overview of Nancy's prodigious and brilliant scholarship, ongoing collaborations, and enduring preoccupations suggests, her limitless curiosity fueled a rigorous and dialectical intellectual project that sought new directions while consistently building upon existing knowledge.

\section{Extending Abelmann's Scholarship on Transnational Asia}

In order to honor her spirit, Jesook Song, Laura Nelson, Yoonjung Kang, and Eleana Kim co-organized panels at the 2016 American Anthropological Association Annual Meeting (Song, Nelson, and Kang) and the 2017 Association for Asian Studies Annual Conference (Song and Kim). Both of the events were double panels, with papers dedicated to the memory of Nancy. In February 2018, Song, Nelson, and Kim convened a workshop at the Center for Critical Korean Studies at the University of California, Irvine, entitled, "Korea Ethnography Now: Building on the Legacy of Nancy Abelmann." The presenters and discussants who participated in the three events included Chungkang Kim, Jiyeon Kang, Jin-kyung Park, Seo Young Park, Dafna Zur, Jin-Kyung Lee, Laurel Kendall, Nicole Constable, Erica Vogel, Jinhee Lee, Martin Manalansan, Nan Kim, Jun Yoo, Seung-kyung Kim, Nicholas Harkness, June Hee Kwon, Jin-Heon Jung, Dohye Kim, Jeongsu Shin, Ga Young Chung, and Agnes Sohn. Those who were familiar with Nancy know that she was an amazing connector-of people, ideas, projects, and institutions. The people who participated in these panels thus represent just a few of the numerous nodes and connections that made up Nancy's multiple scholarly and personal networks.

As a way of remembering her legacy, this "Reflections" section features essays by Jiyeon Kang and Nan Kim, who were mentored by and collaborated with Nancy. These papers were first presented at the 2017 AAS panels, and the works represent just two of the many contributions that were made at the three events, which collectively attempted to reflect and refract Nancy's numerous personal and scholarly contributions. The two articles included in this section are fitting illustrations of two central domains of Nancy's influence.

The first is the phenomenon of educational transmigration and the ethnography of higher education. Kang's piece, "Nancy Abelmann: Anthropologist, Citizen, and Thinker in/on the Global University," traces Nancy's trajectory from The Melodrama of Mobility to The Intimate University, to their comparative project on the globalization of higher education. In this paper, she analyzes South Korean media discourses and representations of Asian exchange students in South Korean universities to build on Nancy's project of understanding the dynamics of race and class, as well as the promises of a liberal education in American universities, which have been aggressively recruiting international students for the past decade. Kang locates a shift in the reception and representations of international students in South Korea from an initial embrace of them as optimizers of South Korea's global status and cultural diplomats, bringing economic and social capital to South Korean universities. By 2008, however, discourses highlighted the problematic dependence of South Korean universities on Chinese students, and the students also became objects of opprobrium, for embodying illiberal (Chinese) nationalist 
values. Conspicuously left out of these discourses was any concern for the students as students or the quality of their education. Kang deftly connects unfolding dynamics of racialized tensions and competing Korean and Chinese nationalisms within their global and regional contexts - namely, a stratified global education market that positions South Korea as a "second choice" for Chinese students, and cultural and economic shifts related to the rise of post-reform China.

The second domain of Nancy's legacy that is reflected in this section is the study of social movements in the context of transnational Korea. Kim's experimental and touching piece, "The Color of Dissent and a Vital Politics of Fragility in South Korea," beautifully interweaves her personal reflections with a sophisticated intellectual engagement with Nancy's work. She draws upon Echoes of the Past, Epics of Dissent to analyze the culture of mass protest in South Korea, unpacking the potential implications of the yellow ribbon, an iconic symbol for a diverse array of dissent groups, in particular the dramatic 2016-17 Candlelight demonstrations, which led to the ousting of President Park Geun-hye. Kim's essay brings crucial attention to the ways in which Park's "motherly" characterization in the presidential campaign was criticized as contradictory during the Candlelight protests for Sewol Ferry Disaster victims and Baek Namgi's death by police violence, by Korean Women Peasants Associations or demonstrators who pushed strollers while in rallies. The signature contribution Kim offers is the notion of "a vital politics of fragility." This notion serves as a double intervention in that it revisits minjung subjectivity and the minjung movement, which are conventionally represented as militant and fierce. In addition, it challenges the perception of fragility as a sign of political, if not emotional, weakness. Fragility, for Kim, has an enabling power not only through the symbol of the yellow ribbon but also in connecting to the "fragile cosmopolitans" that Nancy was drawn to most recently-those of South Korean youth caught up in the hypercompetitive hothouse of education, neoliberal deregulation, and the disregard of the state. If Kim's piece is inspired by Nancy's contemplation of fragility as a way of thinking of vitality in the context of political movements against state violence in both senses of infrastructure and brutality, it offers a transnational framework for understanding parallel disasters beyond Korea. One can think of countless examples here, such as the Grenfell Tower fire in London (2017), the Costa Concordia tragedy (2012), Syrian refugees drowning in the Mediterranean (2016-), the BP oil spill (2010), the Chernobyl nuclear disaster (1986), or the 3/11 Fukushima triple disaster (2011).

Both articles help us to remember Nancy's irrepressibly lively and deeply compassionate spirit, as a grounded intellectual, creative force, and rigorous academic. It was the rare combination of her personal and intellectual gifts - and her generosity as a friend, advisor, mentor, and colleague - that helped to foster the work, lives, and networks of so many scholars who were fortunate to know her. Kang and Kim's essays extend insights from Nancy's rich oeuvre, offering new directions for Korean and transnational Asian studies, and we hope they will motivate future scholars to return to Nancy's writing, and inspire some of the keen curiosity, animated engagement, and perspicuity that made Nancy so memorable and so special to so many. 